\title{
Depression, suicidal motivation and suicidal ideation among individuals with asthma: a cross-sectional study
}

\author{
Vanessa Serva Vázquez ${ }^{1 \wedge}$, Valmar Bião de Lima $^{1} \wedge$, Luane Marques de Mello ${ }^{2}$, Drielle Caroline Bidu Duarte ${ }^{1 \wedge}$, \\ Thaís Dantas Saback de Oliveira ${ }^{1} \wedge$, Álvaro Augusto Cruz $^{1 \wedge}$
}

${ }^{1}$ ProAR Foundation and Federal University of Bahia, Salvador, Brazil; ${ }^{2}$ Ribeirão Preto Medical School of University of São Paulo, Ribeirão Preto, Brazil

Contributions: (I) Conception and design: VS Vázquez, VB Lima, LM Mello, ÁA Cruz; (II) Administrative support: VS Vázquez; (III) Provision of study materials or patients: ÁA Cruz; (IV) Collection and assembly of data: VS Vázquez, VB Lima, DCB Duarte, TD Saback de Oliveira, ÁA Cruz; (V) Data analysis and interpretation: VS Vázquez, VB Lima, LM Mello, ÁA Cruz; (VI) Manuscript writing: All authors; (VII) Final approval of manuscript: All authors.

Correspondence to: Vanessa Serva Vázquez. Programa para o Controle da Asma na Bahia (ProAR), Centro de Saúde Carlos Gomes, Rua Carlos Gomes 270, $7^{\circ}$ andar, Salvador, Bahia 40060-330, Brazil. Email: vannvazquez@gmail.com.

Background: Asthma is a chronic disease associated with risk of depression and suicidal events. The present study estimated the frequency of depression, suicidal motivation (SM) and suicidal ideation (SI) and identified clinical and psychosocial factors associated with these outcomes among individuals with asthma.

Methods: Cross-sectional study of a non-probabilistic sample of 1,358 adults with asthma and controls without asthma. Asthma severity and asthma control were assessed by a physician according to WHO (2009) and GINA (2012) criteria. Depression, SM and SI were screened by Beck Depression Inventory (BDI). Psychosocial factors were evaluated by a Community Violence Questionnaire, a Social Support Scale, a Stress Perceived Scale and a Resilience Scale. Chi-Square Test, and logistic regression models were performed to evaluate association between variables and outcomes.

Results: Among all participants, 222 (16.30\%) had depression, 331 (24.40\%) SM and 73 (5.40\%) SI. There were 138 (12.10\%) individuals with mild depression and SM, and 14 (1.20\%) with mild depression and SI. After adjustment, severe asthma (SA) increased the chance of depression by $53.00 \%$ whereas mild to moderate asthma (MMA) increased by eleven-fold the likelihood of SI. Perception of low social support increased the chance of depression (OR 3.59; 95\% CI, 2.44-5.28) and low resilience by (OR 2.96; 95\% CI, 2.00-4.38); distress increased the odds of SM by 37.00\%, and low affective support perception raised the likelihood of SI by (OR 6.82; 95\% CI, 1.94-2.90).

Conclusions: Asthma, whether mild to moderate or severe, increased the chance of depression and SI. It is noteworthy that individuals with mild depression and MMA are at greater risk for SM and SI. Among the psychosocial variables, perception of low social support and low resilience were the variables associated with depression; distress impacted on SM, and the perception of low affective support raised the chance of SI.

Keywords: Severe asthma (SA); depression; suicidal motivation (SM); suicidal ideation (SI); resilience

Submitted Oct 31, 2020. Accepted for publication Sep 16, 2021.

doi: $10.21037 /$ jtd-20-3197

View this article at: https://dx.doi.org/10.21037/jtd-20-3197

\footnotetext{
^ ORCID: Vanessa Serva Vázquez, 0000-0003-1700-7586; Valmar Bião de Lima, 0000-0001-8479-3666; Luane Marques de Mello, 00000002-4462-8364; Drielle Caroline Bidu Duarte, 0000-0002-3719-3382; Thaís Dantas Saback de Oliveira, 0000-0002-9681-8477; Álvaro Augusto Cruz, 0000-0002-7403-3871.
} 


\section{Introduction}

Asthma is a chronic noncommunicable disease that affects approximately 339 million people worldwide (1). Its main symptoms are shortness of breath, wheezing, and cough, which may worsen at night, in the morning upon awakening and during physical activity (2).

Depression is also a major public health problem and one of the most common asthma comorbidities, particularly among individuals with severe asthma (SA) (2-7). According to Jiang et al. (3), it is possible to highlight three main approaches: studies that analyze the incidence of asthma in individuals with depression, morbidity of depression in patients with asthma and studies that investigate the association between asthma and depression considering the role of inflammatory responses.

Suicidal behaviors are associated with major depression, and it is related to chronic diseases such as asthma. According to Lessa et al., suicidal ideation (SI), suicide plan and suicide attempts are the most studied behaviors among individuals with asthma (8-14).

To date, we found no studies of suicidal motivation (SM) among individuals with asthma. Commonly, SM is studied as the reason or as the motive someone's committed suicide and it is searched in suicide notes (15). However, in the present study SM indicates disinterest in life and it was characterized by depression symptoms $(16,17)$. SM may be related to a hostile, competitive, unequal, oppressive social environment. Moreover, having a chronic disease, living in poverty, and having little social ties contribute to the weakening of one's relationship with life (18).

The suicidal events investigated in the present study are SM and SI. We hypothesized that depression, SM and SI are associated with asthma. It is understood that psychosocial variables such as community violence, high perception of stress and social support also aggravate the mental health of individuals. Therefore, the aim of this study was to estimate the frequency of depression, SM and SI in a sample of individuals with asthma and controls without asthma, and to identify clinical and psychosocial factors associated with these outcomes.

We present this manuscript in accordance with the STROBE reporting checklist (available at https://dx.doi. org/10.21037/jtd-20-3197).

\section{Methods}

\section{Study design and sample characterization}

This is a cross-sectional study performed with data of the
ProAR asthma cohort (Program for control of Asthma in Bahia-Brazil), collected between 2013 and 2015. It is a non-probabilistic sample of adults, 18 years and older, with asthma and controls without asthma recruited by a trained research team to perform the screening of the study population. All individuals were residents of Salvador or Lauro de Freitas, Bahia, Northeastern Region of Brazil.

Participants with SA were outpatients from the ProAR Cohort. As part of the program, they receive free medication for asthma control, and they are assisted by a multiprofessional team. The phenotypes of these patients are untreated SA (before being enrolled in the program), difficult-to-treat SA and treatment resistant SA, but they do not make continuous use of oral corticosteroids (19). Neither does Montelukast make up our medication protocol for the treatment of asthma. In addition, all participants were conscious and well oriented by the time of the interview.

ProAR operates within the scope of the Unified Health System of Brazil (SUS). In the beginning of its activities, in 2003, patients enrolled were evaluated by specialists and were included if they presented SA according to contemporary classifications, as described in detail previously $(19,20)$. Clinical symptoms such as cough, wheezing, dyspnea, and reversibility of symptoms using bronchodilators were considered, according to the Global Initiative for Asthma (GINA, 2012) (21).

Individuals with mild to moderate asthma (MMA) and participants without asthma were recruited in different public locations of great flow of pedestrians, with the intent to enroll individuals from the general population. Posters, banners and newspaper advertisements were also used. They were asked if they ever had asthma. Even with negative responses, all participants underwent interviews and clinical examination.

Pregnant women, individuals with terminal diseases such as advanced neoplasms, with stroke, with congestive heart failure (CHF) syndrome, myopathies, lung diseases (beyond asthma) and other diseases that cause dyspnea, persons with allergy to medications available for asthma, as well as individuals with neurological and psychiatric problems were excluded (19).

A total of 1,450 individuals were considered eligible, but among them 92 were excluded because they did not answer to the Beck Depression Inventory (BDI), leading to a sample of 1,358 participants (Figure 1).

\section{Severity and astbma control assessment}

During the survey all participants were assessed for severity 


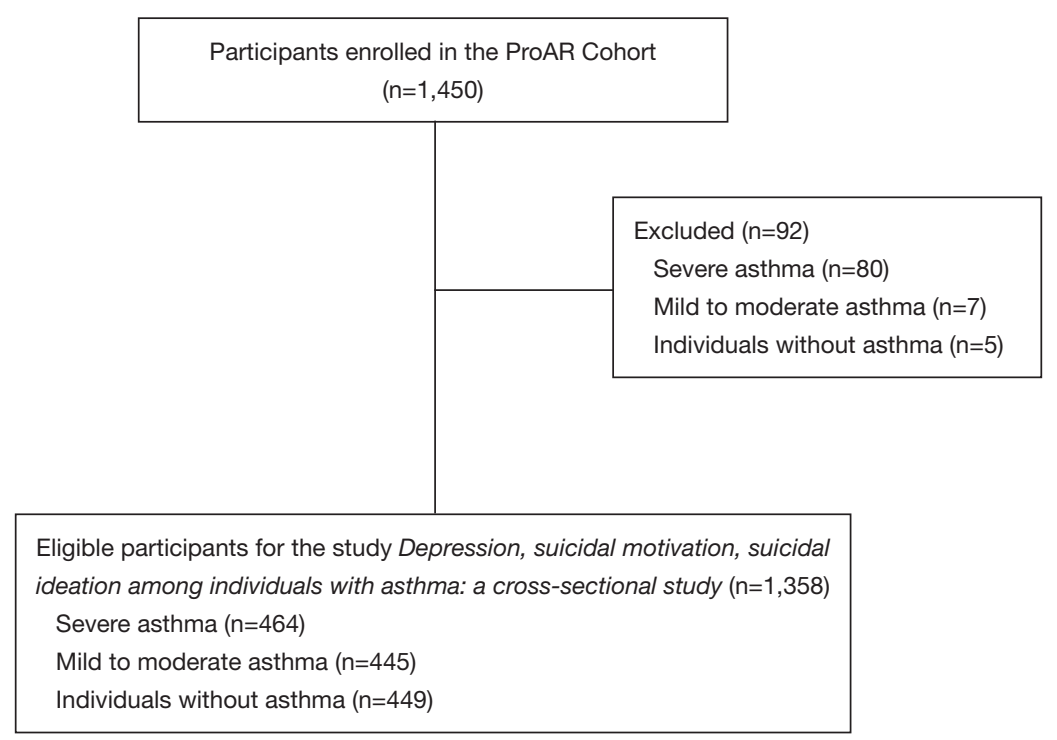

Figure 1 Selection process.

and asthma control by physicians. ProAR participants had their medical records reviewed by two physicians. In case of disagreement about asthma diagnosis, a third specialist was consulted (22).

Asthma severity was evaluated according to criteria proposed by experts to the World Health Organization (WHO) published in 2010. It considered symptoms control, regularity of treatment, doses of medication, form of use of inhalation devices, adherence to treatment and comorbidities and pulmonary function (23). Participants were classified according to asthma diagnosis, namely: SA, MMA, or individuals without asthma.

Asthma control was assessed based on clinical manifestations of the disease according to GINA (2012). It investigates the frequency of daytime asthma symptoms, as well as awakening at night due to asthma, frequency of need for medication to relieve symptoms, limitation of activities and pulmonary function assessed by spirometry $(24,25)$.

These criteria indicate whether asthma is well controlled, when symptoms are not reported; partially controlled, when one or two symptoms were reported, and uncontrolled when three or more symptoms were referred (25). In the present study subjects were classified in two different groups: controlled asthma, and uncontrolled asthma. This latter group also included participants with partially controlled asthma.

\section{Psychosocial measures}

The socio-demographic variables analyzed were age, self-reported sex, self-reported skin color, marital status, education level, occupation, and monthly family income.

Community violence was investigated by a self-report questionnaire with six yes/no questions adapted from previous studies. The instrument evaluated the exposure to community violence in the form of robbery, beating, murderer, gang disputes and impossibility to leave home due to community violence (26). The total score ranges from 0 to 6 . Zero means no exposure to community violence; (1.0 point) minimal, (2.0 points) moderate, (3.0 points) high and (4.0 to 6.0 points), maximum exposure to violence (26). Social network was assessed by two questions from the questionnaire adapted by Chor et al. It indicates the number of family members and friends who made up the social network and was analyzed by means and standard deviation (27): (I) How many relatives do you feel comfortable with and can talk about almost anything? (If applicable, include spouse, partner or child in this response), (II) How many friends are you comfortable with and can talk about almost anything? (Spouse, partner or children were not included). Perception of social support was assessed by the Social Support Scale, a 19-question Likert scale, originally developed by Sherbourne and Stewart for the Medical Outcome Study (MOS) (28). The five dimensions of social support analyzed were: positive social interaction, emotional support, tangible support (material aid and behavioral assistance), informational support and material support $(28,29)$. The first quartile was adopted as the cutoff point (30). Stress was analyzed by the Perceived 
Stress Scale (PSS), with 14 Likert questions, which answers vary from never, zero, to 4.0 points always. Coping and distress were analyzed separately, according to authors who validated the instruments $(31,32)$. Resilience Scale, made up of 25 propositions, assessed the capacity of psychosocial adaptation to important life events. The higher the score, the higher the resilience $(33,34)$. The results of the stress and resilience questionnaires were analyzed considering the first tertile.

\section{Outcomes}

The BDI is a self-report inventory with 21 groups of frequent depressive symptoms. There are four statements in each group of symptoms, ranging from zero to 3 , indicating the worsening of the symptoms. The total score ranges from zero to 63 , given by the sum of the scores of each item. The cut-off point adopted for depression was 20, due to its best sensitivity and specificity. Scores $\leq 19$ indicate minimal and mild symptoms of depression (MD) (16), here named mild depression (MD), and scores $\geq 20$ indicates moderate to severe depression, here named depression.

SM was assessed by a validated five symptoms subscale from BDI which indicates disinterest in life. The symptoms are pessimism, SI, social withdrawal, indecision and loss of libido. It ranges from zero to 15 . The cut-off point for SM is $\geq 5(16,17)$.

SI was assessed by 9th item of the BDI. As the first option value is zero, indicating absence of symptom, in this case, any response except the first one, was indicative of SI (16).

\section{Procedures}

Participants gave informed consent before taking part of the study. They were invited to schedule exams and interviews, when they were asked to read, discuss and sign a written informed consent, if they understood and agreed, they underwent laboratory tests, spirometry, a medical consultation, nutritional and psychosocial assessments.

Individuals with SI had psychological support right after the interview and were referred to psychological care services. When necessary their families were contacted. These procedures occurred with the consent of the participants.

\section{Statistical analysis}

Statistical Package for the Social Sciences - SPSS 21 was used. Descriptive analyzes of socio-demographics, clinical and psychosocial characteristics of the whole sample were carried out with verification of means, standard deviations and proportions. Associations among the variables were performed by Chi-Square Test for nominal and qualitative variables, as well as logistic regression models.

\section{Ethical statement}

The study was conducted in accordance with the Declaration of Helsinki (as revised in 2013) and was approved by the Research Ethics Committee of the Medical School of UFBA, case \# 099/2009, amendment \# 032/2014, and by the National Commission of Ethics and Research (CONEP), Case \# 450/2010, and complies with the Helsink Declaration on ethics for clinical research.

\section{Results}

Among 1,358 participants, 1,106 (81.40\%) were women, with a mean age of $44.25 \pm 14.26$ years; $1,244(91.60 \%)$ declared themselves black and mulatto; 807 (59.40\%) were single, widowed or divorced; $1,150(84.70 \%)$ reported a level of education equal and lower to high school, 575 $(42.50 \%)$ had no defined occupation, and the monthly family income of $521(41.10 \%)$ was equal or lower to the minimum wage (Table 1).

The results in Table 2 show that participants have a hard life, and that they live in a hostile environment. The vast majority, 1,314 (96.76\%), reported exposure to some form of community violence. Participants indicated only one person, on average, $1.03 \pm 1.00$, as family support network. Although friends network had more persons, it was still very small. It was made of $3.45 \pm 1.11$ friends. Among participants, $323(23.80 \%)$ had low social support perception, 918 $(67.60 \%)$ had perception of high stress, with a distress mean of $15.57 \pm 5.43$, and a coping mean of $18.46 \pm 5.13$.

Furthermore, low resilience was found in 658 (48.50\%) individuals, $222(16.30 \%)$ had moderate and severe depression symptoms, 331 (24.40\%) had SM, and 73 (5.40\%) reported SI. SA was diagnosed in 464 (34.17\%) participants, MMA was diagnosed in 445 (32.77\%), and 449 (33.06\%) were individuals identified as not having asthma. Although asthma severity calculation showed a total of 909 asthmatics, asthma control assessment was performed with 900 participants because 9 participants failed to perform spirometry. Thus, among the 900 participants with asthma, $727(80.78 \%)$ had uncontrolled asthma and 173 (19.22\%) 
Table 1 Socio demographic characteristics of the sample of adults with asthma and with no asthma from Salvador, Brazil

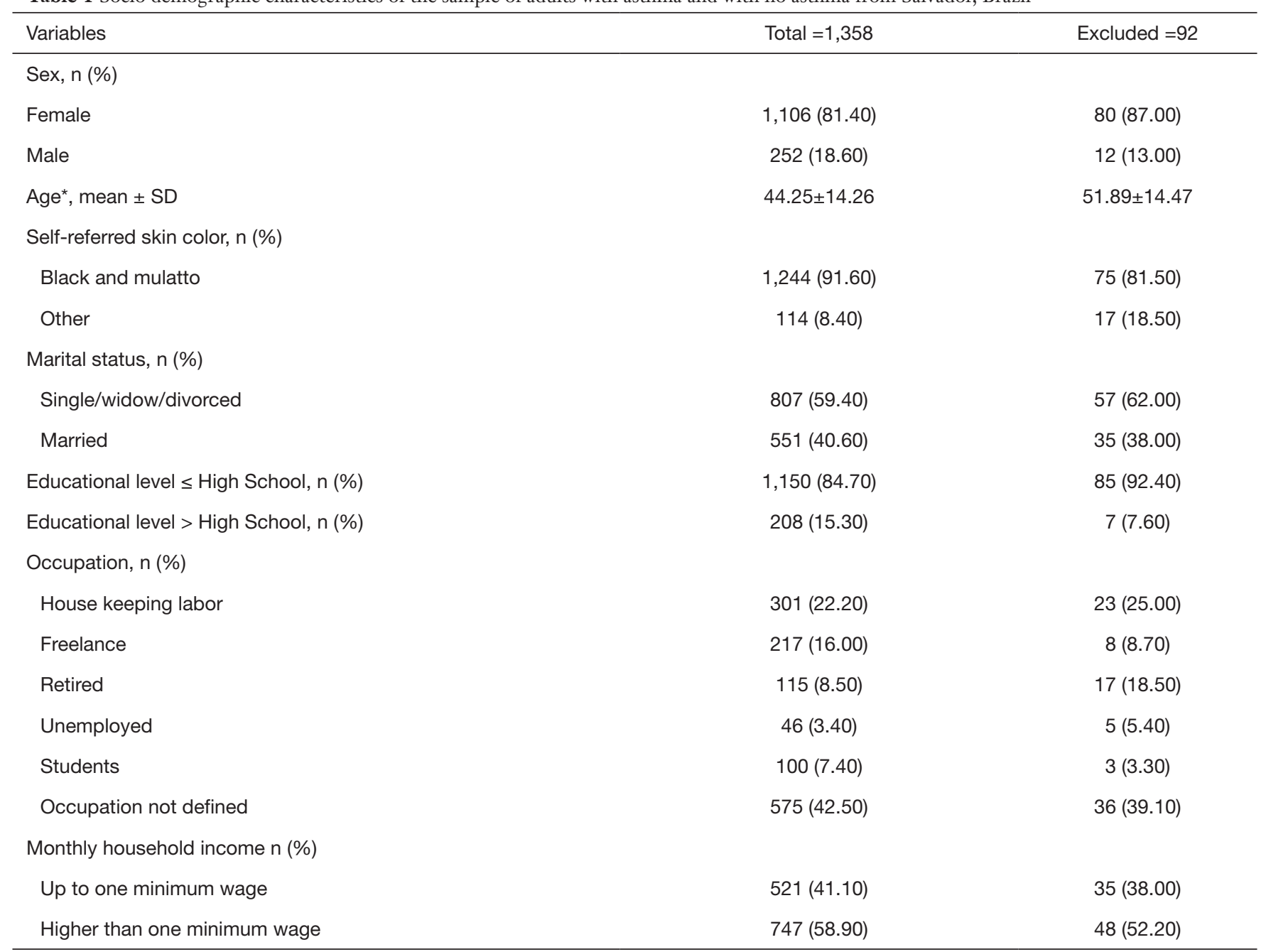

*, age in years, mean \pm standard deviation. Minimum wage (MW): during the data collection the Brazilian MW in US\$ decreased approximately from US\$306.78 to US\$254.19. This was due to the exchange rate variation in Brazil. Occupation was analyzed with information from 1,354 participants and monthly household income with information from 1,268 participants due to missing data.

had controlled asthma.

Considering the entire study population, the majority of participants with depression had SM, 193 (86.90\%), and $59(26.60 \%)$ had SI. Individuals with depression were more likely to have SM (OR 48.10; 95\% CI, 31.30-73.90) and SI, (OR 29.00; 95\% CI, 15.80-5.10). However, a considerable number of participants with MMD were found to present SM 138 (12.10\%), and SI 14 (1.20\%) (Table 3).

Table 4 shows that asthma severity was associated with depression ( $\mathrm{P}=0.000), \mathrm{SM},(\mathrm{P}=0.000)$, and with $\mathrm{SI}(\mathrm{P}=0.037)$. Asthma severity also increased the frequency of the participants with the highest proportions of depression, SM and SI found among individuals with SA.
Among all individuals with depression, SM and SI, asthma was found respectively in 182 (81.98\%), 241 (72.80\%), and $55(75.30 \%)$ participants. Asthma control was associated with depression ( $\mathrm{P}=0.046)$ and $\mathrm{MS}(\mathrm{P}=0.000)$. Uncontrolled asthma was found among 154 (86.50\%) individuals with depression and $212(88.70 \%)$ with SM.

Our main findings are shown in Table 5. Logistic regression models (ORs) were performed to investigate the influence of exposure variables on the prediction of the outcomes.

SA increased the likelihood of depression (OR 1.70; 95\% CI, 1.22-2.38), and the perception of low social support was the psychosocial variable associated with the highest 
Table 2 Psychosocial and clinical characteristics of the sample of adults with asthma and with no asthma from Salvador, Brazil

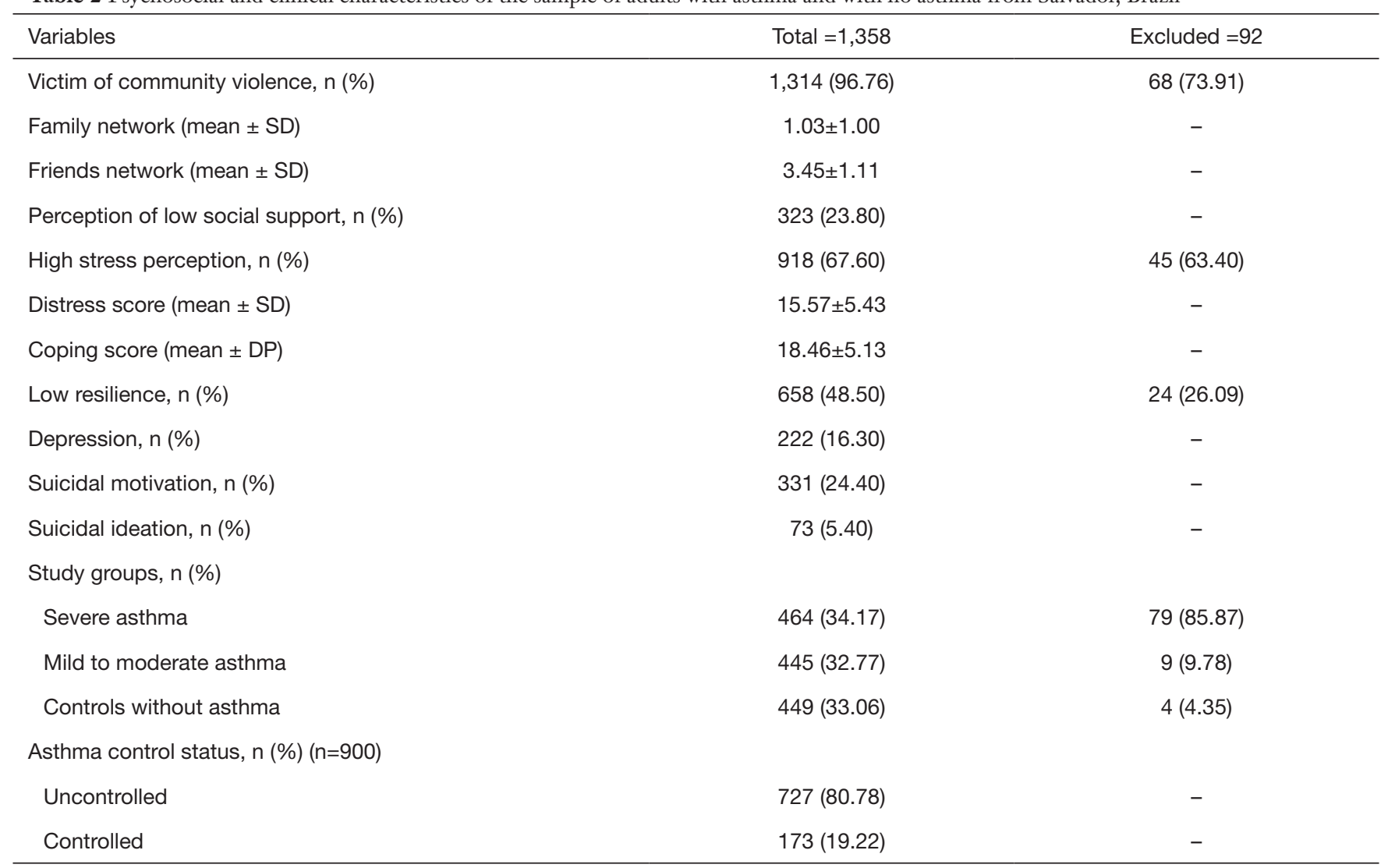

Community violence, at least one report; percep. low social support $<67$; percep. high stress $\geq 32$; low resilience $<133$; depression $\geq 20$; $\mathrm{MS} \geq 5$; IS $\geq 1$. Asthma severity calculation considered a total of 909 asthmatics, but asthma control assessment was performed with 900 because 9 participants failed to perform spirometry.

Table 3 Association between depression, suicidal motivation and suicidal ideation in a sample of adults with asthma and with no asthma from Salvador, Brazil

\begin{tabular}{|c|c|c|c|c|c|}
\hline Variables & Total, $n=1,358$ & Depression, 222 (16.30\%) & Mild depression, 1,136 (83.70\%) & $P$ value & OR $95 \% \mathrm{Cl}$ \\
\hline Without suicidal motivation & $1,027(75.60)$ & $29(13.10)$ & $998(87.90)$ & & \\
\hline Suicidal ideation & $73(5.40)$ & $59(26.60)$ & $14(1.20)$ & 0.000 & $29.00(15.80-53.10)$ \\
\hline Without suicidal ideation & $1,285(94.60)$ & $163(73.40)$ & $1,122(98.80)$ & & \\
\hline
\end{tabular}

Chi-square test; $\mathrm{P}<0.05$. Individuals with scores $\leq 19$ in the BDI (Beck Depression Inventory) were included in the mild depression group.

chance of depression (OR 4.79; 95\% CI, 3.54-6.49). When adjusted for income, age, education, occupation, exposure to levels of community violence, resilience, perceived social support and stress, asthma still increased the likelihood of depression (OR 1.53; 95\% CI, 1.03-2.28), as well as poor education (OR 2.09; 95\% CI, 1.09-4.00); perceived low social support (OR 3.59; 95\% CI, 2.44-5.28); and low resilience in (OR 2.96; 95\% CI, 2.00-4.38). The number of friends suggested to be a protective factor (OR $0.83 ; 95 \%$ CI, 0.72-0.96) and a larger network of friends decreased the likelihood of depression.

Low family income increased the odds of SM (OR 1.62; 95\% CI, 1.25-2.10), but when adjusted for age, education, occupation, income, exposure to levels of community 
Table 4 Association between asthma severity, asthma control status and depression, suicidal motivation and suicidal ideation in a sample of adults from Salvador, Brazil

\begin{tabular}{|c|c|c|c|c|c|c|}
\hline Variables & Depression, n=222 (\%) & $P$ value & Suicidal motivation, $\mathrm{n}=331(\%)$ & P value & Suicidal ideation, $\mathrm{n}=73$ (\%) & $P$ value \\
\hline Severe asthma & $112(50.45)$ & & $150(45.30)$ & & $35(47.90)$ & \\
\hline Mild to moderate asthma & $70(31.53)$ & & $91(27.50)$ & & $20(27.40)$ & \\
\hline No asthma & $40(18.02)$ & & $90(27.20)$ & & $18(24.70)$ & \\
\hline Uncontrolled & $154(86.50)$ & & $212(88.70)$ & & $43(78.20)$ & \\
\hline Controlled & $25(13.50)$ & & $27(11.30)$ & & $12(21.80)$ & \\
\hline
\end{tabular}

Chi-square tests; $P<0.05$. The analysis with the studied groups was carried out with 1,358 participants, including individuals without asthma. Asthma control status comparisons were performed with 900 asthmatic individuals. Among these, 179 had depression, 239 had suicidal motivation, and 55 reported suicidal ideation.

Table 5 Unadjusted and adjusted odds ratio for depression, suicidal motivation, and suicidal ideation ( $\mathrm{n}=1,358)$ in a sample of adults with asthma and with no asthma from Salvador, Brazil

\begin{tabular}{|c|c|c|c|}
\hline Variables & Unadjusted $\mathrm{OR}^{\star}$ & $\beta$ & Adjusted OR* \\
\hline \multicolumn{4}{|l|}{ Depression 222(16.30\%) $)^{\ddagger}$} \\
\hline Severe Asthma & $1.70(1.22-2.38)$ & 0.428 & $1.53(1.03-2.28)$ \\
\hline Education level $\leq 2$ nd grade & $2.43(1.45-4.09)$ & 0.738 & $2.09(1.09-4.00)$ \\
\hline Low percep. social support & 4.79 (3.54-6.49) & 1.280 & $3.59(2.44-5.28)$ \\
\hline Friend's network increase & - & -0.179 & $0.83(0.72-0.96)$ \\
\hline \multicolumn{4}{|l|}{ Suicidal motivation $331(24.40 \%)^{+}$} \\
\hline Age & - & 0.033 & $1.03(1.01-1.06)$ \\
\hline Distress & - & 0.315 & $1.37(1.20-1.56)$ \\
\hline Mild to moderate asthma & $1.73(0.98-3.05)$ & 2.407 & $11.01(2.01-61.05)$ \\
\hline Age & - & -0.063 & $0.93(0.89-0.99)$ \\
\hline Low percep. affective support. & $4.90(3.03-7.92)$ & 1.920 & $6.82(1.94-23.90)$ \\
\hline $\begin{array}{l}\text { Number of community members beaten or injured by } \\
\text { weapon or knife }\end{array}$ & - & 0.110 & $1.11(0.96-1.28)$ \\
\hline
\end{tabular}

$\mathrm{P}<0.05$; * OR 95\% Cl; ${ }^{\ddagger}$, model adjusted for income, age, education, occupation, exposure to levels of community violence, resilience, perceived social support and perceived stress; ${ }^{+}$, model adjusted for age, education, occupation, income, exposure to levels of community violence, number of times assaulted, perceived stress and resilience; ${ }^{\S}$, model adjusted for income, age, education, occupation, exposure to levels of violence, perceived social support, number of friends, coping and resilience. 
violence, number of times assaulted, perception of stress and resilience, only distress increased significantly the likelihood of SM (OR 1.37; 95\% CI, 1.20-1.56).

Bivariate analyses showed that MMA raised by (OR 1.73; 95\% CI, 0.98-3.05) the odds for SI, but after adjusting for income, age, education, occupation, exposure to violence, perceived social support, number of friends, coping and resilience, asthma was the variable with the greatest impact on this outcome. It heightened the chance of SI by elevenfold (OR 11.01; 95\% CI, 2.01-61.05).

The perception of low affective support was also important and was associated with a seven-fold higher chance of SI (OR 6.82; 95\% CI, 1.94-2.90). It was also found that age was a protective factor (OR $0.93 ; 95 \% \mathrm{CI}$, $0.89-0.99)$. In this sample, younger individuals had greater probability to have SI.

Although most of the participants reported having suffered any form of violence, this variable did not show statistical significance after adjustment.

\section{Discussion}

This study reports a high frequency of depression, SM and SI and identified clinical and psychosocial factors associated with these outcomes in a sample of adults with well characterized asthma of different severities and control levels.

Individuals with depression had higher frequencies of SM and SI, confirming the likelihood of suicidal behaviors or events among depressed individuals. But it is important to note that the high ORs observed may be related to the collinearity of the investigated outcomes, as they come from the same instrument for tracking symptoms of depression.

However, the existence of participants with mild depression presenting SM and SI indicates the importance of protocols with screening depressions instruments, to identify severe symptoms of depression, regardless an outlined and phenomenological state of moderate and severe depression.

Our present findings are aligned with results of earlier studies conducted with individuals with chronic diseases, which also identified participants with SI or other suicidal events that did not meet the diagnostic criteria for depression $(11,35,36)$.

Depression was more common in individuals with asthma as in previous studies which found percentages between $4.1 \%$ and $47.7 \%$ (10-12,37-39). Individuals with MMA had higher percentage than participants with no asthma but the individuals with SA were the participants with greater frequencies. The results also show that among all individuals with depression, 182 (81.98\%) were asthmatics. This high proportion is related to the fact that our sample is composed by SA cases and not a population-based sample.

SM was also elevated among individuals with SA 150 $(45.30 \%)$ and considering all individuals with SM, 241 $(72,80 \%)$ were asthmatic.It indicates that almost three quarters of this group showed disinterest in life. SI were also greater in asthmatics with the severe form of the disease, $35(47.90 \%)$, and was higher among all individuals with asthma, $55(75.30 \%)$, than preceding estimates that varied between $7.6 \%$ to $30.4 \%$ (10-12,35,36,40-42).

The main findings of this work are related to the demonstration of the influence of clinical and psychosocial covariates on the occurrence of the studied outcomes. It is noteworthy, that resilience and the perception of social support are commonly studied as protective factors, but here we investigated the low resilience and the perception of little social support to assess its impacts.

The probability of depression was increased by SA, poor education, perceived poor social support, low resilience, and having few friends.

SA increased (OR 1.53; 95\% CI, 1.03-2.28) the chance of depression. This result is similar to the ORs calculated for studies that analyzed the effects of asthma on depression (OR 1.52, 95\% CI, 1.30-1.79), as presented in a metaanalysis by Jiang et al. (3).

Asthma impacts on depression possibly because the exacerbations and limitations compromise functional capacity and quality of life (35). Hence, asthma symptoms are experienced as negative adverse life events and suffering, which can precipitate depression because it causes physical and mental distress. In addition to this, psychological stress would cause an increase in inflammatory markers, modulated by cytokines, and this process may be shared by asthma and depression (3).

Poor education heightened in two-fold the odds for depression. We consider three interdependent pathways to explain this association. First, as it is a sample of 900 $(67,00 \%)$ individuals with asthma, it is believed that the disease may have limited the participants educational achievements. Asthma flare-ups require medical care, as well as time to recover, and that impacts in school performance due to absenteeism. Second, level of education is an important social indicator. In particular, poor education might restrict work and life opportunities, limiting individuals to reach a better income. Third, schooling is 
related to healthy habits and better health conditions. It contributes to the development of cognitive repertoire, which enables individuals to face better adverse situations and use adequate problem-solving mechanisms, in line with the adversities experienced $(43,44)$.

The perception of low social support increased the chance of depression almost four times and was the psychosocial variable more strongly associated with the occurrence of this outcome. Possibly these results are related to the limited possibilities for interaction, due to the small social network of participants.

Social support promotes social inclusion, provides bonhomie and information. It is associated to positive affect improving self-esteem. Investing in social positive interactions and strengthen social ties are important. Safe relationships favor stress reduction and help individuals to develop self-control and feelings of adequacy. Social support also benefits the reduction of symptoms of mental disorders such as depression $(27,28,43)$. Being able to count on close persons increases the feeling of acceptance. It favors adherence to treatment, control of symptoms, and better quality of life of asthma patients.

Low resilience increased the likelihood of depression almost three times. Low resilience is associated with severe depressive states, probably because of the challenge to respond to adverse situations. Likewise, it shows the individual's difficulty in rebuilding from traumatic or stressful experiences $(33,45)$.

Resilience is considered a dynamic, multi-determined process related to life experiences (33). It can be learned and strengthened through interventions. Training programs can benefit the improvement of problem-focused coping strategies to decrease stress and increase the individual's ability to adapt and enabling them to maintain healthy development in adverse situations $(46,47)$.

Distress was the variable associated with an increased chance of SM. Asthma, poor education, low family income, unemployment, precarious work, poor social support and exposure to community violence are important elements of stress experienced by the studied population that compromise quality of life and social well-being.

Highest frequencies of SM were found among individuals with SA and uncontrolled asthma indicating the burden of the disease on the interest in life.

Among the psychosocial variables, the exposure to community violence is probably the one which promotes most distress. Of all participants, 1,314 (96.80\%) indicated exposure to any form of violence. This number is much higher than those found in a survey conducted in Rio de Janeiro and São Paulo, biggest cities of Brazil, where the exposures were respectively $63.6 \%$ and $59.4 \%$ (48). It possibly reflects sociodemographic differences between the samples evaluated.

Knowing how unpredictable, uncontrolled and overloaded are individual's lives, reveals how people are affected by stress. The PSS measured the degree to which individuals perceived various situations as stressful $(31,32)$. Distress and coping are the two dimensions of stress. Distress indicates the negative perception of these events. Coping indicates the ability to handle and manage stressful life situations, in order to preserve well-being (49-52).

SM and SI are part of a suicidal crisis. Feelings of anguish, helplessness, and lack of perspective are also present. Suicide might be perceived as a solution to an unbearable living situation that goes beyond the personal capacity of reaction and adaptation. Suicide ideas and other suicidal behaviors can be considered a rejection or an avoidance of a painful life $(15,53)$. In this sense, it is understood how distress impacts on the individual's interest in life and increases SM. The feeling of impossibility of changing its own life may outline a suicidal context due to the psychache caused by experiences of suffering (53).

The occurrence of SI was higher among individuals with MMA, those younger, and with low perception of affective support. These results are in line with population studies in which younger people were more likely to have SI $(13,54)$.

The perception of poor affective support increased the chance of SI almost seven-fold. The perception of low affective support may be related to functional impairment and restrictions imposed by asthma, even among individuals with MMA. Affective support is the dimension of social support characterized by the physical demonstration of love and affection $(27,28)$.

Social support is a protective factor, which help individuals developing sense of identity and belonging. The lack of social and affective support may characterize emotional abandonment and can be expressed and observed in different ways. It is possible to be experienced and reported as isolation and preference for loneliness among adolescents (55), or it can be referred as unloving, ingratitude when elderly complain the distance of descendent $(56,57)$.

Cross-sectional and longitudinal studies showed that asthma was associated with higher frequencies and increased risk of IS $(10-12,14,35,36,42)$.

MMA unexpectedly increased in 11-fold the chance of SI. This result is relevant because it indicates the impact of 
the disease on mental health and highlights the importance of proper care of these individuals. Previously, the highest odds of SI had been reported by Goodwing \& Eaton in a cohort study which asthma increased (OR 2.33; 95\% CI, 1.03-5.25) the chance of SI. According to the authors, depression had little effect on this outcome (11).

Given the unexpected strong association between MMA and SI, with no concurrent association with depression on SM, we must acknowledge some of these individuals' dyspnea may not be truly asthma, but the result of their anxiety.

Individuals with MMA were diagnosed with asthma during the research visit, when they underwent medical consultations. In contrast, patients with SA were treated in ProAR for at least six months by a multi-professional team and had been receiving asthma medication for symptom's control since they are enrolled in the program.

Mild to moderate asthma comprises the majority of individuals diagnosed with asthma. The frequency of symptoms is low, they progress more rarely with loss of lung function, hospitalizations or death. However, patients usually have poor adherence to treatment and are at risk of severe exacerbations $(37,58)$ creating great distress.

Treatment patterns of individuals with MMA, as well as disease burden were investigated in a prospective crosssectional multinational study conducted in eight countries across Europe, Asia and America. The diagnosis of asthma was defined on GINA treatment criteria, Step 1 and Step 2. The authors identified that doctors and patients tended to underestimate the lack of control of asthma symptoms, as well as the frequency of these symptoms, however $25 \%$ of patients had no symptom control and $12.5 \%$ of the participants reported at least one moderate to severe exacerbation in the previous year of the survey. In addition, participants with uncontrolled MMA were more likely to have anxiety and depression. This group of individuals also had significant asthma-related losses and costs due to absenteeism in school and work due to the need for medical and hospital appointments (38).

The present study adds knowledge to the field of asthma, depression and suicidal behaviors and events. As in other studies with asthmatics adults, the sample had a majority of women but further analysis showed that gender was not statistically significant in this population. Nonetheless, these results should not be extrapolated to adult males.

This study differs from previous because it reported the association between depression and SM, which had not been studied before among individuals with asthma, and SI considering the severity and asthma control. This study reported the occurrence of important psychosocial variables, such as resilience, perception of social support and stress in relation to depression, SM and SI among subjects with asthma. It is noteworthy that the results here presented come from a large sample of individuals well characterized for asthma by specialists. Further, psychosocial assessment was performed by a team of trained psychologists.

\section{Study limitations}

The study design does not allow the identification of a temporal or causal relationship between the independent variables and depression, SM and SI. The study sample was not selected randomly, but the study was announced in many different public places to make sure the recruitment of participants with MMA and individuals without asthma represented the general population.

\section{Conclusions}

Severe and uncontrolled asthma were associated with higher frequencies of depression, SM and SI. The chance of having depression was significantly increased by SA, poor education, perceived low social support and low resilience. Distress increased the chance of SM, indicating the perception of overload and lack of control of adverse life events may be associated with great suffering.

The most relevant observation of this study, is the increased occurrence of SI, mainly among MMA patients, followed by perception of low affective support. It is advisable to investigate the occurrence of SM and SI even among individuals with mild symptoms of depression and asthma. Strengthening of social ties should be promoted and coping repertoire shall be developed to improve resilience.

\section{Acknowledgments}

Funding: This work was supported by Postgraduate Program in Medicine and Health, Medical School of Bahia, Federal University of Bahia, Salvador, Bahia, Brazil. This study was financed in part by the Coordination for the Improvement of Higher Education Personnel - Brazil (CAPES) - [Finance Code 001] and Tecnológico do Brasil (CNPq) - Grant \# 471057/2014-2.

\section{Footnote}

Provenance and Peer Review: This article was commissioned 
by the GARD Section Director Yousser Mohammad for the "GARD Section" published in Fournal of Thoracic Disease. The article has undergone external peer review.

Reporting Checklist: The authors have completed the STROBE reporting checklist. Available at https://dx.doi. org/10.21037/jtd-20-3197

Conflicts of Interest: All authors have completed the ICMJE uniform disclosure form (available at https://dx.doi. org/10.21037/jtd-20-3197). The "GARD Section" was commissioned by the editorial office without any funding or sponsorship. VVS reports doctoral scholarship from Coordination for the Improvement of Higher Education Personnel - Brazil (CAPES) during the conduct of the study. Bidu DC reports grants from National Council for Scientific and Technological Development (CNPq), during the conduct of the study. AAC reports grants and personal fees from Brazilian Research Council (CNPq), grants from GlaxoSmithKline, during the conduct of the study; personal fees from Sanofi, personal fees from Boehringer Ingelheim, personal fees from AstraZeneca, personal fees from Chiesi, personal fees from Mylan, personal fees from Novartis, personal fees from GSK, personal fees from Eurofarma, personal fees from Mantecorp, outside the submitted work. AAC serves as the unpaid director of the series as an unpaid editorial board member of Fournal of Thoracic Disease. The other authors have no conflicts of interest to declare.

Ethical Statement: The authors are accountable for all aspects of the work in ensuring that questions related to the accuracy or integrity of any part of the work are appropriately investigated and resolved. The study was conducted in accordance with the Declaration of Helsinki (as revised in 2013) and was approved by the Research Ethics Committee of the Medical School of UFBA, case \# 099/2009, amendment \# 032/2014, and by the National Commission of Ethics and Research (CONEP), Case \# $450 / 2010$, and complies with the Helsink Declaration on ethics for clinical research.

Open Access Statement: This is an Open Access article distributed in accordance with the Creative Commons Attribution-NonCommercial-NoDerivs 4.0 International License (CC BY-NC-ND 4.0), which permits the noncommercial replication and distribution of the article with the strict proviso that no changes or edits are made and the original work is properly cited (including links to both the formal publication through the relevant DOI and the license). See: https://creativecommons.org/licenses/by-nc-nd/4.0/.

\section{References}

1. Global Asthma Network, Globalasthmareport, Available online: http://globalasthmare port.org/

2. World Health Organization. Asthma Fact sheet. Up date, May. Available online: https://www.who.int/news-room/ fact-sheets/detail/asthma

3. Jiang M, Qin P, Yang X. Comorbidity between depression and asthma via immune-inflammatory pathways: a metaanalysis. J Affect Disord 2014;166:22-9.

4. Gao YH, Zhao HS, Zhang FR, et al. The Relationship between Depression and Asthma: A Meta-Analysis of Prospective Studies. PLoS One 2015;10:e0132424.

5. Scott KM, Von Korff M, Ormel J, et al. Mental disorders among adults with asthma: results from the World Mental Health Survey. Gen Hosp Psychiatry 2007;29:123-33.

6. Lehrer P, Feldman J, Giardino N, et al. Psychological aspects of asthma. J Consult Clin Psychol 2002;70:691-711.

7. Baiardini I, Sicuro F, Balbi F, et al. Psychological aspects in asthma: do psychological factors affect asthma management? Asthma Res Pract 2015;1:7.

8. Iessa N, Murray ML, Curran S, et al. Asthma and suiciderelated adverse events: a review of observational studies. Eur Respir Rev 2011;20:287-92.

9. Barker E, Kõlves K, De Leo D. The relationship between asthma and suicidal behaviours: a systematic literature review. Eur Respir J 2015;46:96-106.

10. Goodwin RD, Demmer RT, Galea S, et al. Asthma and suicide behaviors: results from the Third National Health and Nutrition Examination Survey (NHANES III). J Psychiatr Res 2012;46:1002-7.

11. Goodwin RD, Eaton WW. Asthma, suicidal ideation, and suicide attempts: findings from the Baltimore epidemiologic catchment area follow-up. Am J Public Health 2005;95:717-22.

12. Goodwin RD, Olfson M, Shea S, et al. Asthma and mental disorders in primary care. Gen Hosp Psychiatry 2003;25:479-83.

13. Nock MK, Borges G, Bromet EJ, et al. Cross-national prevalence and risk factors for suicidal ideation, plans and attempts. Br J Psychiatry 2008;192:98-105.

14. Franklin JC, Ribeiro JD, Fox KR, et al. Risk factors for suicidal thoughts and behaviors: A meta-analysis of 50 years of research. Psychol Bull 2017;143:187-232.

15. Rogers JR, Bromely JL, McNally CJ, et al. Content 
analysis of suicide notes as a test of the motivational component of the existencial-constructivist model of suicide. J Couns Dev 2007;85:182-8.

16. Cunha JA. Manual of the Portuguese version of the Beck Scales. São Paulo: Psychologist's House, 2011.

17. Cunha JA, Oliveira MS, Argimon IIL. The Evaluation of Depressive Symptoms in Alcoholics. Psycho 1996;27:117-28.

18. Marx K. About suicide. São Paulo: Boitempo, 2006.

19. Cruz AA, Riley JH, Bansal AT, et al. Asthma similarities across ProAR (Brazil) and U-BIOPRED (Europe) adult cohorts of contrasting locations, ethnicity and socioeconomic status. Respir Med 2020;161:105817.

20. Ponte E, Souza-Machado A, Franco R, et al. Asthma and allergic rhinitis control Program in Bahia: a model of integration between care, teaching and research. Rev Baiana Public Health 2004;28:124-32.

21. Global Initiative for Asthma (GINA). Global strategy for asthma management and prevention; 2012.

22. Pinheiro GP, de Souza-Machado C, Fernandes AGO, et. al. Self-reported smoking status and urinary cotinine levels in patients with asthma. J Bras Pneumol 2018;44:477-85.

23. Bousquet J, Mantzouranis E, Cruz AA, et al. Uniform definition of asthma severity, control, and exacerbations: document presented for the World Health Organization Consultation on Severe Asthma. J Allergy Clin Immunol 2010;126:926-38.

24. Global Initiative for Asthma (GINA). Global strategy for asthma management and prevention. Available online: https://ginasthma.org/wp-content/uploads/2019/01/2012GINA.pdf

25. Jesus JPV, Lima-Matos AS, Almeida PCA, et al. Obesity and asthma: clinical and laboratory characterization of a common combination. J Bras Pneumol 2018;44:207-12.

26. Alves Gda C, Santos DN, Feitosa CA, et al. Community violence and childhood asthma prevalence in peripheral neighborhoods in Salvador, Bahia State, Brazil. Cad Saude Publica 2012;28:86-94.

27. Chor D, Griep RH, Lopes CS, et al. Social network and social support measures from the Pró-Saúde Study: pretests and pilot study. Cad Saude Publica 2001;17:887-96.

28. Sherbourne CD, Stewart AL. The MOS social support survey. Soc Sci Med 1991;32:705-14.

29. Griep RH, Dóra C, Faerstein E, et al. Test-retest reliability of measures of social network in the "Pró -Saúde" Study. Rev Saude Publica 2003;37:379-85.

30. Marques dos Santos L, Neves dos Santos D, Rodrigues LC, et al. Maternal mental health and social support: effect on childhood atopic and non-atopic asthma symptoms. J
Epidemiol Community Health 2012;66:1011-6.

31. Luft CD, Sanches Sde O, Mazo GZ, et al. Brazilian version of the Perceived Stress Scale: translation and validation for the elderly. Rev Saude Publica 2007;41:606-15.

32. Cohen S, Kamarck T, Mermelstein R. A global measure of perceived stress. J Health Soc Behav 1983;24:385-96.

33. Wagnild GM, Young HM. Development and psychometric evaluation of the Resilience Scale. J Nurs Meas 1993;1:165-78.

34. Pesce RP, Assis SG, Avanci JQ, et al. Cross-cultural adaptation, reliability and validity of the resilience scale. Cad Saude Publica 2005;21:436-48.

35. Druss B, Pincus H. Suicidal ideation and suicide attempts in general medical illnesses. Arch Intern Med 2000;160:1522-6.

36. Clarke DE, Goodwin RD, Messias EL, et al. Asthma and suicidal ideation with and without suicide attempts among adults in the United States: what is the role of cigarette smoking and mental disorders? Ann Allergy Asthma Immunol 2008;100:439-46.

37. Ding B, Small M. Disease Burden of Mild Asthma: Findings from a Cross-Sectional Real-World Survey. Adv Ther 2017;34:1109-27.

38. Galić K, Dodaj A, Ćorluka-Čerkez V, et al. Study of depression and anxiety in patients with asthma and chronic obstructive pulmonary disease. Psychiatr Danub 2019;31:112-7.

39. Coban H, Aydemir Y. The relationship between allergy and asthma control, quality of life, and emotional status in patients with asthma: a cross-sectional study. Allergy Asthma Clin Immunol 2014;10:67.

40. Bedolla-Barajas M, Pulido-Guillén NA, Vivar-Aburto B, et al. Is suicidal ideation associated with allergic asthma and allergic rhinitis? J Bras Pneumol 2018;44:31-5.

41. Favreau H, Bacon SL, Joseph M, et al. Association between asthma medications and suicidal ideation in adult asthmatics. Respir Med 2012;106:933-41.

42. Chung JH, Kim SH, Lee YW. Suicidal ideation and suicide attempts among asthma. Ann Gen Psychiatry 2016;15:35.

43. Batty GD, Kivimäki M, Bell S, et al. Psychosocial characteristics as potential predictors of suicide in adults: an overview of the evidence with new results from prospective cohort studies. Transl Psychiatry 2018;8:22.

44. Batty GD, Whitley E, Deary IJ, et al. Psychosis alters association between IQ and future risk of attempted suicide: cohort study of $1,109,475$ Swedish men. BMJ 2010;340:c2506.

45. Wood SK, Bhatnagar S. Resilience to the effects of social 
stress: evidence from clinical and preclinical studies on the role of coping strategies. Neurobiol Stress 2015;1:164-73.

46. Rutter M. Resilience as a dynamic concept. Dev Psychopathol 2012;24:335-44.

47. Shin YC, Kim SM, Kim H, et al. Resilience as a Protective Factor for Depressive Mood and Anxiety among Korean Employees. J Korean Med Sci 2019;34:e188.

48. Ribeiro WS, Mari Jde J, Quintana MI, et al. The impact of epidemic violence on the prevalence of psychiatric disorders in Sao Paulo and Rio de Janeiro, Brazil. PLoS One 2013;8:e63545.

49. Faro A. Confirmatory factor analysis of three versions of the Perceived Stress Scale (PSS): a population-based study. Available online: https://www.scielo.br/j/prc/a/9WxhmCvs BVZdqTLdwbjq6Ly/?lang=pt

50. Nia ME, Aliloo MM, Ansarin K. The role of stress and coping strategies in the emergence of asthma and moderating effects of gender in this illness. Procedia Soc Behav Sci 2010;5:910-4.

51. Barton C, Clarke D, Sulaiman N, et al. Coping as a mediator of psychosocial impediments to optimal management and control of asthma. Respir Med 2003;97:747-61.

Cite this article as: Vázquez VS, Lima VB, Mello LM, Duarte DCB, Saback de Oliveira TD, Cruz ÁA. Depression, suicidal motivation and suicidal ideation among individuals with asthma: a cross-sectional study. J Thorac Dis 2021;13(10):6082-6094. doi: $10.21037 /$ jtd-20-3197
52. Lazarus R, Folkman S. Stress appraisal and coping. New York: Springer, 1984.

53. Chavez-Hernández AM, Leenaars AA. Edwin S Shneidman and modern suicidology. Available online: http://www. scielo.org.mx/scielo.php?script=sci_arttext\&pid=S018533252010000400008\&lng=es

54. Kessler RC, Borges G, Walters EE. Prevalence of and risk factors for lifetime suicide attempts in the National Comorbidity Survey. Arch Gen Psychiatry 1999;56:617-26.

55. Endo K, Ando S, Shimodera S, et al. Preference for Solitude, Social Isolation, Suicidal Ideation, and SelfHarm in Adolescents. J Adolesc Health 2017;61:187-91.

56. Beutel ME, Klein EM, Brähler E, et al. Loneliness in the general population: prevalence, determinants and relations to mental health. BMC Psychiatry 2017;17:97.

57. Silva RMD, Sousa GS, Vieira LJES, et al. Suicidal ideation and attempt of older women in Northeastern Brazil. Rev Bras Enferm 2018;71 Suppl 2:755-62.

58. Global Initiative for Asthma (GINA). Global strategy for asthma management and prevention. Available online: https://ginasthma.org/wp-content/uploads/2020/06/ GINA-2020-report_20_06_04-1-wms.pdf 